\title{
FLEXIBLE OPTIMIZATION IN THE PROCESS OF PLANNING AND PRODUCTION CONTROL
}

\section{Borislav Gordić}

Original scientific paper

Process of production planning and control has been treated as a process influencing the management as well as adaptibility and flexibility of a business system in the conditions of major and intensive changes. This necessarily asks for the need of correction and adjustment of production plans and application of optimization methods and techniques, in order to provide a continuous adjustment of an enterprise to the needs of the environment and its own state. Mathematical basis of flexible planning and control is given, which among other things indicates the need of adapting the optimization methods to actual conditions in the production system and its environment through simulation techniques Model of discrete corrective dynamizing optimization is presented and tested where the dynamising programming is used as the starting optimization method, while the simulation is applied as an additional technique for the optimization of the basic operational production plan correction.

Keywords: discrete corrective dynamizing programming; flexible planning and control; production adaptability; profit rate

Fleksibilna optimizacija u procesu planiranja i praćenja proizvodnje

Izvorni znastveni članak Planiranje i praćenje proizvodnje tretirano je kao proces s utjecajem na upravljanje te prilagodljivost i fleksibilnost poslovnog sustava u uvjetima većih i intenzivnih promjena. To nužno uvjetuje potrebu korekcija i usklađivanja planova proizvodnje uz primjenu metoda i tehnika optimizacije, a u funkciji kontinuiranog prilagođavanja poduzeća potrebama okoline i svojem stanju. Data je matematička osnova prilagodljivog planiranja i praćenja koja između ostalog ukazuje na potrebu prilagođavanja metoda optimizacije stvarnim uvjetima u proizvodnom sustavu i njegovom okruženju primjenom tehnike oponašanja. Predstavljen je i testiran model diskretnog korektivnog dinamizirajućeg optimiranja gdje je korišteno dinamizirajuće programiranje kao polazna metoda optimizacije, a oponašanje kao dodatna tehnika za optimizaciju korekcije osnovnog operativnog plana proizvodnje.

Ključne riječi: diskretno korektivno dinamizirajuće programiranje; klizno planiranje i praćenje; prilagodljivost proizvodnje; profitna stopa

\section{Introduction}

It is a known fact that today's available methods and optimization techniques set conditions and restrictions that almost always more or less deviate from the actual issues of the problem being solved. Therefore, it is considered to set up the models of treatment of the system and its processes which are based on logical and empirical knowledge. In this way and with the inclusion of the specific features of each system can be achieved a greater degree of realization of chosen optimal solutions during their implementation in practice $[1,2,3]$.

Another reason in favour of the modelling of systems and processes before optimizing future solutions for production plans, is that this provides better choice and better optimization of solutions. This should be done not only by relying on the established base and principles in previous periods, but also by using the data from current situation in the system and its environment, with bigger or smaller connection with the previously established rules and parameters.

Modelling of the planning and control process should define planning periods for a production/business system, frequency and time periods when plans should be modified and aligned. After that, optimization of planning and control may ensure that the interests of the system are realized to the greatest possible extent, by realizing the set plans with optimal flexibility and by meeting the needs of the environment.

Flexible planning and control can serve as a general model and the starting point for modelling of the planning and control process for individual cases, because it can connect mathematical optimization methods and practical developments in the form of changes in the system and the environment during realization. The basic principle of flexible planning and control is based on periodic harmonization of components and activities relating to all levels of operational plans.

Each of them is corrected and adjusted to the changes occurring during the phase of their lower plans for the next planning period, not necessarily in line with calendar time. This should be done so that they are treated in timely manner and so that minimum deviation from, or even an increase of, the planned results is ensured. In this way, flexible planning and control combines theoretical basis and practical conditions for optimization of production/business activities.

Flexible planning and control, together with some of the methods and techniques of production programming, should be a model of adaptable planning and production control which would help find optimal plans and optimal planning and control process. This should be done so that changes, disturbances and risks in the system and its environment are dealt with to the greatest extent possible and that solutions, with necessary corrections, are optimized for these situations to ensure adaptability and flexibility of the production system.

In other words, it is necessary to find a model of planning and control that can be adapted, to the greatest extent possible, to the real, current conditions in the system and its surroundings in an optimal way. In practice, there are always larger or smaller disruptions and changes resulting in deviations in realization with respect to optimally planned results. Standard methods and optimization techniques are not designed in a way that allows flexibility and adaptability of the production system $[4 \div 6]$. 


\section{Criteria of optimization}

To create an optimization model of planning and control, it is necessary to know which criteria and standards will be used for the optimization. Using individual criteria facilitates the application of mathematical methods and optimization techniques, but also shows that different criteria for optimization produce different results, and sometimes these are significantly different [7]. This shows that it is necessary to use synthetic criteria, put together using the appropriate algorithm and several individual criteria, thus advising that the synthetic criteria of optimization should consist of 2 to 4 individual criteria.

Each production system aims to achieve the greatest possible cost effectiveness of production and business activities, i.e., the biggest possible difference between revenues and costs. At the same time, it has to be realized with higher volume of production, that is, of revenue, and better capacity utilization, implying that market needs have to be met to a greater extent. With so established goals, a relatively simple solution seems to be the synthetic criterion for successfulness of productionbusiness $U P$, defined according to the Eq. (1)

$U P=I K \cdot P F$

where: $I K$ - capacity utilization (measured as decimal expression of percentage); $P F$ - profit rate (measured as decimal expression of percentage).

In this way, financial and material criteria are combined because capacity utilization IK shows indirectly how much the volume of production is realized as revenue on the market and how rationally the production capacity is developed. The profit rate indicates a relation between income and expenses, showing operational and financial successfulness of the production system.

In addition, it is a known fact that greater and more continuous use of capacity provides greater stability and reliability of the production, implying that the quality of products is less likely to decline and thus also cutting back the production costs and providing better depreciation of machinery and equipment. In addition, it should be noted that the term capacity means all available capacities which a production system has at its disposal, or if it uses capacities of third parties.

\section{Dynamic programming}

Due to the increasing changes in the environment, it is certain that some of the mathematical models of dynamic programming should be used as a method and optimization technique in the process of planning and control, because time is an important factor for the issues of planning and control.

Dynamic programming requires the process control which is gradual and conducted over a period of time and in several stages, in such a manner that the planning optimization for a larger number of periods - stages takes place in several steps that precede the end, as it is shown in Fig. 1.

If the indicator $\Phi$ is taken as a criterion of dynamic programming in production system $S$ for a period $T$, and if the system is operated over time through solution $U$, it raises the issue of choice of $U t$ by periods $t$ in order to achieve a maximum or a minimum of $\Phi$.

In case of planning, this means determining plans $P_{1}$, $P_{2}, \ldots, P_{k}$ for the period $T$, which consists of $m$ periods/stages. If the $x_{i j}$ solution is given for $i$ period and $P_{i}$ plan, then the vector in Eq. (2) is solution $P_{i}$.

$\overrightarrow{X_{(\imath \jmath)}}=\left(x_{i 1}, x_{i 2}, \ldots \ldots x_{i k}\right)$

Vectors $\overrightarrow{X_{1}}, \overrightarrow{X_{2}}, \ldots, \overrightarrow{X_{k}}$ correspond to a set of solutions $U_{1}, U_{2}, \ldots, U_{k}$ and define function $\Phi$, which needs to be maximized or minimized, according to the Eq. (3)

$\Phi=\Phi\left(U_{1}, U_{2}, \ldots U_{k}\right)$

Looking at the production system $S$, of all possible states $S_{t}$ by periods $t$ attention should be paid to the initial $S_{\text {start }}$ and final $S_{\text {end }}$ state wherein for each, both at the beginning and at the end there are more options, as it is shown in Fig. 1. The task of dynamic programming is to find the optimal solution $U^{*}$ from the set of solutions $U$, which the system $S$ converts to a final solution $S_{\text {end }}^{(n)}$ from the initial conditions $S^{(0)}$ in stages and periods, by means of optimizing $\Phi$.

In essence, dynamic programming represents management by stages, i.e. solving tasks in which each stage/period requires making appropriate decisions. They basically do not have to be optimal for each stage, since the goal is complete optimality of the whole treated period.

When performing $k$ step of the operation, step $(k-1)$ is uncertain, and this stage assumes a range of solutions marked according to the Eq. (4)

$S_{k-1}^{(1)} ; \quad S_{k-1}^{(2)} ; \quad \ldots \ldots \ldots ; \quad S_{k-1}^{(j)}$

For each solution in Eq. (4), it is necessary to determine the decision in $k$ step $U_{k}$, which then becomes one of the following decisions by the Eq. (5)

$U_{k}\left(S_{k-1}^{(1)}\right) ; \quad U_{k}\left(S_{k-1}^{(2)}\right) ; \quad \ldots \ldots \ldots \quad U_{k}\left(S_{k-1}^{(j)}\right)$

Now every solution $S_{k-1}^{(j)}$ depends on the solution made in $(k-2)$ step, whereby possible solutions for this step are given in the Eq. (6)

$S_{k-2}^{(1)} ; \quad S_{k-2}^{(2)} ; \quad \ldots \ldots \ldots ; \quad S_{k-2}^{(j)}$

so the decision $U_{k-1}$ according to the Eq. (6) should be sought in the line shown in the Eq. (7)

$U_{k-1}\left(S_{k-2}^{(1)}\right) ; U_{k-1}\left(S_{k-2}^{(2)}\right) ; \ldots \ldots ; \quad U_{k-1}\left(S_{k-2}^{(j)}\right)$

If this continues further, one encounters the first step which contributes by its decision or solution in reaching an optimal total solution. 


\section{Discrete corrective dynamizing optimization}

One way to obtain dynamics in production plans' programming in the sense of adaptability is to use flexible planning and control by using the linear programming method. In the sense of flexibility, such a model can be called dynamizing programming, of which the schematic presentation is given in Fig. 2.

\section{AREA OF POSSIBLE SOLUTIONS}

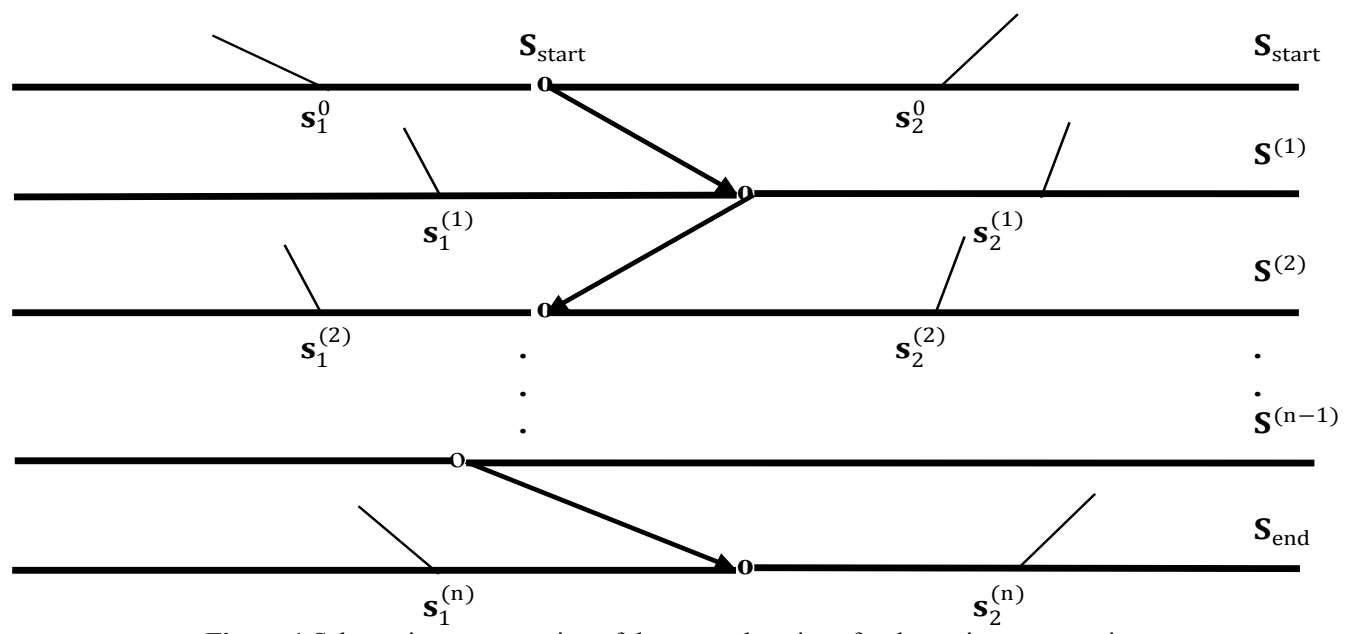

Figure 1 Schematic representation of the general settings for dynamic programming

Regarding the model of dynamizing programming, in the case when the basic plan is a monthly plan and the first higher level plan is a quarterly plan, three monthly plans of one quarter $P_{i}, P_{i+1}$ and $P_{i+2}$ are optimized, and by linear programming in accordance with the upper and lower limits of demand $Q_{i j}^{g}$ and $Q_{i j}^{d}, Q_{i+1, j}^{g}$ and $Q_{i+1, j}^{d}$ and $Q_{i+2, j}^{g}$ and $Q_{i+2, j}^{d}$. This includes the limitations of other resources relevant to programming and optimization of plans. With expiry of the period of higher level plan corrections $(T k) v$ reprogramming has to be carried out for three plans for the next three parts of a quarter $R_{i+1}$, $R_{i+2}$ and $R_{i+3}$ with corrected limits of demand $\left(Q_{i+1, j}^{g}\right)^{\prime}$ and $\left(Q_{i+1, j}^{d}\right)^{\prime}, \quad\left(Q_{i+2, j}^{g}\right)^{\prime}$ and $\left(Q_{i+2, j}^{d}\right)^{\prime}$ and $\left(Q_{i+3, j}^{g}\right)^{\prime}$ and $\left(Q_{i+3, j}^{d}\right)^{\prime}$.

Correction of these limits should be made according to expected additional orders received in the previous periods $Q d_{i j}, Q d_{i-1, j}$ etc., and in accordance with other available resources.

The selected planning period can be treated again from the moment of decision-making, or the solution to change the current plan can be determined by simulation $[8 \div 12]$.

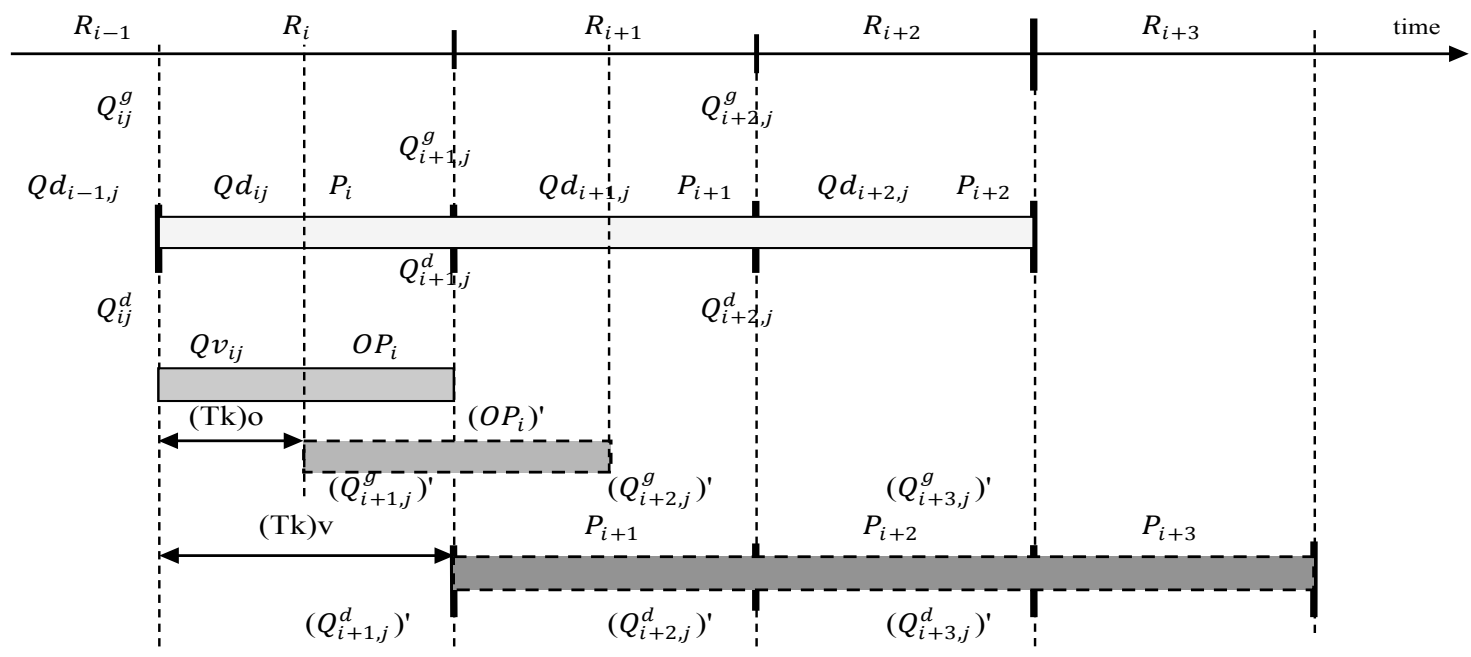

Figure 2 Schematic presentation of the dynamizing programming model

If the correction of the operational plan $O P_{i}$ is done with expiry of a period of correction (Tk)o, then by simulation it will be determined which part of the unexpected additional orders $Q v_{i j}$ could be realized in the current operating period, and thereby the corrected operational plan is obtained $\left(O P_{i}\right)^{\prime}$.
In case of new optimization of plans for any significant changes or disorders for selected period through dynamizing programming it can significantly impede the realization of the production and cause additional costs and activities, particularly in the process of planning and control. Therefore is indicated the need 
for selection and forming of a model that may be applicable in a number of types and conditions of production [13].

Such a model of corrective optimization, by which the plans could be corrected with the application of simulation and the flexible process of planning and control, is called discrete corrective dynamizing optimization.

However, before designing a model of discrete corrective dynamizing optimization, it is necessary to establish criteria and standards for determining the optimal correction of plans.

The correction that is selected as the most favourable, optimal correction of an operational plan is the one at which the biggest difference in revenue and profit increase will be achieved in relation to the additional costs of planning and control, as follows according to Eq. (8):

$E K=I P P-P T$

where: $E K$ - correction plan efficiency; $P T$ - changes of costs; IPP-index of revenue change $I P$ and profit change $I F$, according to Eq. (9)

$I P P=I P \cdot I F$

The change of costs $P T$ should be taken in the scale of decimal expression of the percentage of the cost change in relation to the costs in the existing plan. The revenue change $I P$ and profit change $I F$, as well as the product of their multiplication according to Eq. (9) are expressed as an index, i.e. as a decimal expression of percentage of change increased by 1 , and thus it is always valid that $I P P>P T$, for the ease of operation.

Changes and disorders are collected and processed in each period of adjustment $(T k) i$ of the basic plan and its checks and corrections are done properly, for each period of correction.

For this purpose, among all realistically possible variants the method of simulation should be used in order to choose solution of plan correction in which the efficiency of correction $E K$ is maximal.
As the variants for the correction of starting basic plan only those are taken that can be implemented in the period of following corrected basic plan.

\section{Mathematical basis of adaptability}

In the application of mathematical methods and optimization techniques reality always more or less adjusts itself to the mathematical model. Therefore, a case might occur, as shown in Fig. 3, that the set representing optimal possibilities-solutions $S_{o}$ not only contains elements from a set of possibilities $S_{i}$, but also parts outside of this set, that is, there is a discrepancy between the optimal elements determined by mathematical programming and real quantity of the elements of optimization.

Therefore, the practice shows that e.g. there is a deficit of certain product in an optimal production program for some period, and on the other hand, a surplus of some products in relation to the real demand. This leads to situations where the production system either cannot deliver a certain quantity of products which are realistically in demand (poor advertising), or there is a surplus of products which are not currently in demand and consequently are placed on the market with poorer financial results. These deviations are not in large percentages nor are they of great value, but they are sufficient for a business system to suffer a direct or indirect damage. Its checks and corrections are done properly, for each period of correction.

For this purpose, among all realistically possible variants the method of simulation should be used in order to choose solution of plan correction in which the efficiency of correction $E K$ is maximal. As the variants for the correction of basic plan starting, only those are taken that can be implemented in the period of the following corrected basic plan.

It can be said that the set of realistic solutions $S_{r}$ is an intersection of sets $S_{i}$ and $S_{o}$, as shown in the Eq. (10), that the set of deviation-error $S_{d}$ is a difference between the set of optimal solutions $S_{o}$ and a set of realistic solutions $S_{r}$, as defined in Eq. (11)

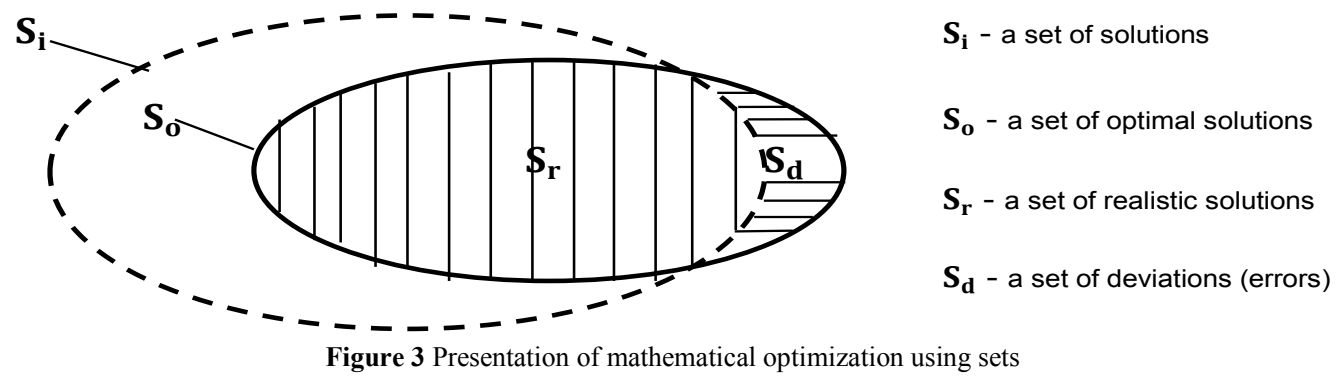

$S_{r}=S_{i} \cap S_{o}=\left\{x \in S_{i} \mid x \in S_{i} \& x \in S_{o}\right\}$

$S_{d}=S_{o} \backslash S_{r}=\left\{x \in S_{o} \mid x \in S_{o} \& x \notin S_{r}\right\}$

In case of discrete corrective dynamizing optimization, whose flow is shown in Fig. 4, for the selected planning period $t_{j}$, the changes $S_{p}$ occurring in the environment and the system during the treated planning period are also taken into account, for each time period of correction $t_{i}$. The same changes are taken into account when optimizing a customized plan for a certain planning period, and the correction of the optimal plan $S_{o_{j}}$ is made as well as its transformation into a customized plan $S_{o_{j}}^{1}$.

Additionally, between sets and subsets of opportunities and solutions there are relations specified in Eqs. (12), (13) and (14), as follows: 
$S_{o_{j}}=S_{o_{i}}+S_{o_{i+1}}+S_{o_{i+2}}$

$S_{o_{j}}^{1}=S_{o_{i+1}}^{1}+S_{o_{i+2}}^{1}+S_{o_{i+3}}$

$S_{o_{i+1}}^{1}=S_{o_{i+1}} \pm S_{k_{i+1}} ; S_{o_{i+2}}^{1}=S_{o_{i+2}} \pm S_{k_{i+2}}$
This means that the corrected, adapted optimal plan $S_{o_{j}}^{1}$ for the treated planning period after the expiry of the first period of correction $t i$ will be, according to the Eq. (13), composed of previously defined, and now customized parts $S_{o_{i+1}}^{1}$ and $S_{o_{i+2}}^{1}$ and this new part $S_{o_{i+3}}$.

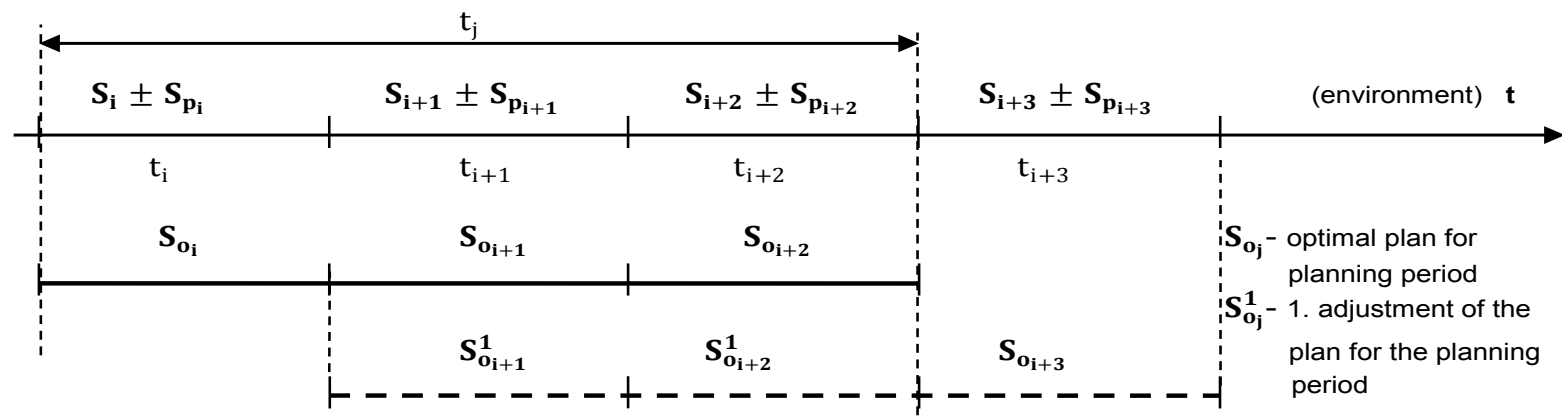

Figure 4 Presentation of the progress of discrete corrective dynamizing optimization

According to the Eq. (14), corrected and adapted parts of the new optimal plan $S_{o_{i+1}}^{1}$ and $S_{o_{i+2}}^{1}$ are the sets which contain parts from previously optimized sets $S_{o_{i+1}}$ and $S_{o_{i+2}}$, as well as those parts from the sets containing changes $\mathrm{S}_{\mathrm{p}_{\mathrm{i}+1}}$ and $\mathrm{S}_{\mathrm{p}_{\mathrm{i}+2}}$, which now represent the sets of corrections $S_{k_{i+1}}$ and $S_{k_{i+2}}$.

If the stated mode is displayed by means of sets in the example for the part of the optimal solution for the planning period, as seen in Figure 5, it can be concluded that the corrected optimal plan $S_{o_{i+1}}^{1}$ is a union of subset $P S_{o_{i+1}}$, as a larger part of the previous optimal plan $S_{o_{i+1}}$, and a part of the set containing changes $S_{p_{i+1}}$ which is called a subset of a set of changes $P S_{p_{i+1}}$, or a set of corrections $S_{k_{i+1}}$, shown in the Eq. (17).

This means that each element $\boldsymbol{x}$ in the corrected part of the optimal plan set $S_{o_{i+1}}^{1}$ is contained either in the subset of the part of previously optimized plan $P S_{o_{i+1}}$ or in a subset of a set of changes $P S_{p_{i+1}}$.

$$
\begin{aligned}
S_{o_{i+1}}^{1}= & P S_{o_{i+1}} \cup P S_{k_{i+1}} \\
& =\left\{x \in S_{o_{i+1}}^{1} \mid x \in P S_{o_{i+1}} \vee x \in P S_{k_{i+1}}\right\}
\end{aligned}
$$

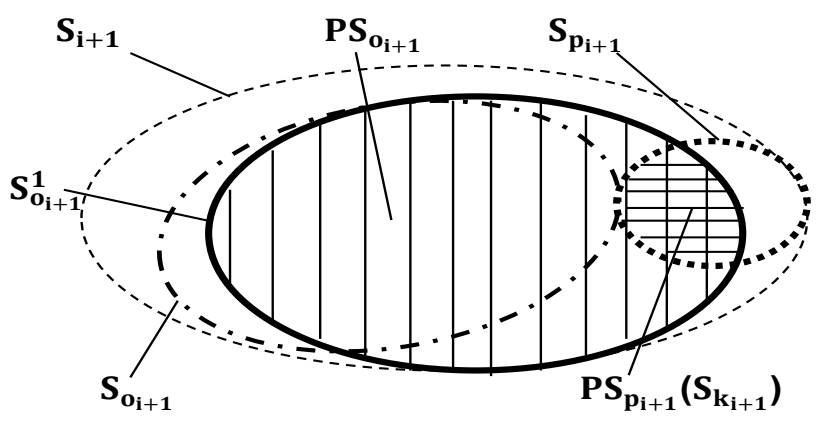

Figure 5 Graphic presentation of settings of corrective optimization using sets

$$
\begin{aligned}
& \mathbf{S}_{\mathbf{i}+\mathbf{1}} \text { - a set of solutions } \\
& \mathbf{S}_{\mathbf{p}_{\mathbf{i}+\mathbf{1}}} \text { - a set of changes } \\
& \mathbf{S}_{\mathbf{o}_{\mathbf{i}+\mathbf{1}}} \text { - an initial optimal plan } \\
& \mathbf{S}_{\mathbf{o}_{\mathbf{i}+\mathbf{1}}}^{\mathbf{1}} \text { - corrected optimal plan } \\
& \mathbf{P S}_{\mathbf{o}_{\mathbf{i}+\mathbf{1}}} \text { - a subset of initial optimal plan } \\
& \mathbf{P S}_{\mathbf{p}_{\mathbf{i}+\mathbf{1}}} \text { - a subset of a set of changes } \\
& \quad \text { (a set of plan corrections } \mathbf{S}_{\mathbf{k}_{\mathbf{i}+\mathbf{1}}} \text { ) }
\end{aligned}
$$

According to the Eq. (16), this means that for the difference of $\operatorname{set} S_{o_{i+1}}^{1}$ and subset $P S_{o_{i+1}}$ it can be said that each element $\boldsymbol{x}$ in the corrected part of the optimal plan set $S_{o_{i+1}}^{1}$ is contained in that set, and at the same time it is not contained in subset $P S_{o_{i+1}}$.

$S_{o_{i+1}}^{1} \backslash S_{o_{i+1}}=\left\{x \in S_{o_{i+1}}^{1} \mid x \in S_{o_{i+1}}^{1} \& x \notin S_{o_{i+1}}\right\}$

from which it can be concluded that this difference consists of elements from the subset of a set of changes $P S_{p_{i+1}}$, as a set of corrections $S_{k_{i+1}}$, in accordance with the Eq. (17),

$S_{o_{i+1}}^{1} \backslash P S_{o_{i+1}}=\left\{x \in P S_{p_{i+1}}\right\}=\left\{x \in S_{k_{i+1}}\right\}$

In other words, a set of corrected optimal plan $S_{o_{i+1}}^{1}$ now includes more realistic elements of solution $\boldsymbol{x}$ as the union of a subset $P S_{o_{i+1}}$ and a subset $P S_{p_{i+1}}$. Then, a subset $P S_{o_{i+1}}$ contains a part of the solutions from a set $S_{o_{i+1}}$ which is corrected with a part of solutions from a subset $P S_{p_{i+1}}$ according to the selected criteria of optimization. Therefore it can be said that the discrete corrective dynamizing optimization will significantly affect the success and flexibility of a production system and business operations in conditions of dynamic changes in the environment and the production system itself, particularly in relation to already known mathematical optimization methods.

\section{Application of adaptable planning}

As the example of discrete corrective dynamizing optimization can be used the case when the basic plan is 
made for a period of one month, with a week as a period of correction of the basic plan, while the first higher plan is a quarterly plan with a period of correction of one month. It is always a starting basic plan which is the first part of the current quarterly plan, whether the plan is a starting one or a corrected one, and it is always determined by the dynamizing programming while the correction of the basic plan is carried out by applying the methods and techniques of simulation.

For the selected example of a discrete corrective dynamizing optimization there are 4 general groups of changes that may occur during the period of correcting the basic plan, which can act positively or negatively as follows:

a) large number of major changes

b) large number of minor changes

c) small number of major changes

d) small number of minor changes.

It is necessary to take all these into account because those types of changes cannot always be treated in the same way and they must be, considering their size and character, sorted according to the period in which they may be included in the treatment. Thus, some may or must be treated already in the first following correction of the basic plan seeking an optimal solution for the corrected basic plan through simulation, while some will be treated only at the correction of the first higher plan.

For each set of changes $P_{i j}$ which appears in the shortest period of correction $T k$, it is first necessary to select the character of each received information about the change. The information character will be positive in case of demand for products and negative in case of disruption in the supply of raw materials, use of energy or reduced capacity due to failure or problems with subcontractors.

If the information on the change has a negative character, it will be taken into treatment at the first following correction of the current plan, and if its character is positive, the information will be classified within the corresponding period of the basic plan - for a period of one month. The actuality of positive information is determined by the required, anticipated deadline for its realization.

Flexibility of the production system in relation to changes in the system itself and its surroundings is always partial, more or less, because of the numerous restrictions and inertia found in the production system. However, it can be safely claimed that by applying discrete corrective dynamizing optimization, plans at all levels will become more objective and closer to reality than with any other model of optimization in the process of production planning and control.

It is also clear that the production system cannot respond to every change, but it can be concluded from the above mentioned that the use of discrete corrective dynamizing optimization enables the system to adapt to dynamic changes more reliably than it is the case with the hitherto known methods and optimization models.

During the corrective optimization of the previously optimized plan it is necessary to decide on the correction plan refinement, that is, in which percentage the existing individual items of the plan should be corrected, in order to obtain solutions of which the optimal one is to be chosen. This should be decided in the following manner:

a) If the difference on data about the upper $Q_{i j}^{g}$ and lower $Q_{i j}^{d}$ limit of the expected demand is relatively large and the number and amount of expected $Q d_{i j}$ and unexpected $Q v_{i j}$ additional orders small, it is necessary to take a larger percentage of the corrections regarding the current size of the plan, for example $10 \div 20 \%$, and so a smaller set of potential solutions will be formed.

b) If the difference on data about the upper $Q_{i j}^{g}$ and lower $Q_{i j}^{d}$ limit of the expected demand is relatively small and the number and amount of expected $Q d_{i j}$ and unexpected $Q v_{i j}$ additional orders large, it is necessary to take a smaller percentage of the corrections regarding the current size of the plan, for example $2 \div 5 \%$, and so a smaller set of potential solutions will be formed.

This is only logical, because if some more precise initial data and information on the expected and unexpected additional orders are available, correction plans with greater correction precision will have to be done, and vice versa. In any case, it will depend on the production system and its environment, in accordance with the objectives of the production system.

\section{Testing of the model of corrective optimization}

For the testing of the method of discrete corrective dynamizing optimization the data from practical example of production of dishes were taken. These data cover several groups of products for the period of the first 6 characteristic months of the year. Testing was done in a way that the results of the production plans optimization were compared with the really achieved results for the selected practical example. For comparison with these results, the following models of production plans optimization were selected:

A - Linear programming

B - Dynamizing programming

C - Linear programming with corrective optimization by simulation

D - Discrete corrective dynamizing programming.

When applying linear programming by simplex method, as model A, for the upper and lower limits of product demand, the data about the dissipation of realization on the market were taken, thus as the upper limit for each considered month the maximum achieved realization of each product was taken, and as the lower limit the lowest achieved realization of that product in the month was taken.

Simplified model of dynamizing programming, as model B, was made in such a way that a part of the expected additional orders, as an expression of changes in the environment, was included in determination of the upper and lower limits of product demand in each month. In this way, a part of the orders which are received in the current month for the first part of the current month were included, while the additional orders for the deliveries in the second part of the current month were excluded from the treatment. By generating the part of additional orders, 
the correction of the upper and lower limits of product demand was made for some $25 \div 50 \%$ of the total share of additional orders for each product in each month and then linear programming by simplex method was applied in these new conditions.

As the third, C model for testing, the simplified model of linear programming with corrective optimization by simulation was taken. According to this model, the initial optimal plan is modified on the basis of the changes - additional, that is, unexpected orders during the current month using the method of simulation. In this model the initial plan is the solution obtained by the above listed A model of linear programming using the simplex method, while the corrections of the current plan were made for all extra orders that had to be realized during the current operational plan.

Discrete corrective dynamizing programming, as model D, was also somewhat simplified for this testing in a way that a part of the additional orders was included into the current operational plan based on the application of flexible planning (by periodic repetition), while the other part, approximately similar to the total share of additional orders for each product in each month, that is, unexpected additional orders, was the basis for the correction of the current plan using the method of simulation. In its essence, it was a combination of dynamizing programming (B model for testing) and corrective optimization using the method of simulation.

For testing the selected models in relation to the results from the practical example the criterion of adaptibility $P G$ was used according to Eq. (18)

$P G=\Sigma \Delta Q_{i} / p$

where: $\Sigma \Delta Q_{i}-$ difference between planned and realized quantities in the decimal expression of percentage; $p-$ number of treated product groups where the adaptibility function $\Phi=\Phi(P G \min )$.

Correction of the operational plans in the tested models $\mathrm{C}$ and $\mathrm{D}$ was made according to the possible, most favourable solutions using the criterion of the smallest profit rate loss GP according to Eq. (19)

$G P=(1-\triangle P F)$

Several case variants in the environment were tested by varying the values of the following parameters: $X$ degree of uncertainty-risk in the environment; $Y$ - share of additional orders; $Z$ - share of emergency orders.

Combinations-variants of cases for testing were obtained by combining the starting and multiplied values of additional $Q d_{i j}$ and emergency $Q v_{i j}$ orders, where: $\mathrm{Y} 1=Q d_{i 1}, \mathrm{Y} 2=2 Q d_{i 1}, \mathrm{Y} 3=3 Q d_{i 1}, \mathrm{Y} 4=4 Q d_{i 1}$, and also $\mathrm{Z} 1=Q v_{i 1}, \mathrm{Z} 2=2 Q v_{i 1}, \mathrm{Z} 3=3 Q v_{i 1}, \mathrm{Z} 4=4 Q v_{i 1}$. In this way, 10 variants-cases were obtained and were tested for each optimization model.

Difference in the results obtained by different optimization models can be seen in the way that the results obtained in the production plans for each running of the program with a different variant are compared with the actual realization from the practical example, as shown in Tab. 1.
Table 1 Optimization model test results for the example of dishes production

\begin{tabular}{|c|c|c|c|c|}
\hline \multirow{2}{*}{ Test variants } & \multicolumn{4}{|c|}{ Deviation in quantity (\%) } \\
\cline { 2 - 5 } & Model A & Model B & Model C & Model D \\
\hline 01. X0Y1Z1 & 7,69 & 4,82 & 6,86 & 4,32 \\
\hline 02. X2Y2Z1 & 9,37 & 4,40 & 8,57 & 3,95 \\
\hline 03. X3Y1Z2 & 10,18 & 6,97 & 8,54 & 6,21 \\
\hline 04. X4Y2Z2 & 11,00 & 4,58 & 9,50 & 4,24 \\
\hline 05. X4Y3Z1 & 11,00 & 5,62 & 9,46 & 4,77 \\
\hline 06. X4Y1Z3 & 11,00 & 8,20 & 9,16 & 7,34 \\
\hline 07. X5Y3Z3 & 11,81 & 6,56 & 10,21 & 5,94 \\
\hline 08. X5Y4Z2 & 11,81 & 6,21 & 11,19 & 5,94 \\
\hline 09. X6Y2Z4 & 12,63 & 9,43 & 11,83 & 8,69 \\
\hline 10. X8Y4Z4 & 14,25 & 7,97 & 12,84 & 7,46 \\
\hline
\end{tabular}

The minimal difference in the obtained profit rate can be determined with corrective optimization models $(\mathrm{B}, \mathrm{C}$ and $\mathrm{D}$ ) in relation to the initial linear programming model (A). This difference was in the range of only 1 to $2 \%$ of the realized nominal profit and it is inevitable if we want to use the flexible model of production planning. This, however, proves at the same time that with corrective, adaptable optimization it is possible to achieve a satisfactory optimum of production, with maximal adjustment to changes and disturbances in the environment.

It can also be concluded that this model of flexible operational production planning and control, as well as the other optimization models in conditions of uncertainty-change, will not always ensure solutions with the $100 \%$ maximum results according to the selected criteria. Nevertheless, it will certainly enable the production system to adjust itself to changes and objective situations with the least deviation from the initial solutions, i.e. from maximally possible results, in a better and easier way than in the case when known similar models are applied.

\section{Conclusion}

Based on the model of flexible planning and production control a model of corrective dynamizing optimization of production plans is made. By applying a linear programming with the periodic alignment in the process of flexible planning and control the dynamic programming of production is obtained and is relatively easy to be applied in every production. The model in a very simple manner and with a high level of successfulness enables the adaptability and flexibility of the production system in the conditions of uncertainty and change.

The models of simulation for the correction of basic optimized operational plans may be different, and mainly depend on the character of production and the mode of production - Make-To-Stock, Make-To-Order, combined, individual, etc., and can provide results from a set of optimal solutions.

Namely, with mathematical optimization, a system is given of $m$ equations and $n$ unknowns,

$\sum_{k=1}^{n} \alpha_{i k} \xi_{k}=\beta_{i} \quad(i=1, \ldots, m)$

where $\alpha_{i k}, \xi_{k}$ and $\beta_{i}$, as the parameters of the production are constants and real numbers, and the linear form

$\boldsymbol{f}(\boldsymbol{x})=\sum_{k=1}^{n} \gamma_{k} \xi_{k}$ 
should find the vector $\left.\boldsymbol{x}=\xi_{1}, \ldots, \xi_{k}\right) \geq 0$ which makes the linear form $\boldsymbol{f}(\boldsymbol{x})$ maximum and satisfies the system of equations $\boldsymbol{A} \boldsymbol{x}=\boldsymbol{b}$ so each vector $\boldsymbol{x}_{\boldsymbol{o}}$ that meets these criteria is the optimal solution.

According to obtained results it can therefore be said that corrective optimization has negligible deviation from the functions of the maximum and thus the obtained solution can be considered as an element of the set of all possible solutions $\boldsymbol{A} \boldsymbol{x}=\boldsymbol{b}, \boldsymbol{x} \geq \boldsymbol{0}$.

Corrective optimization by applying method of simulation is performed according to criteria in the expression $E K=I P P-P T$ (8). In this way the significance of the activities of all the treated processes is included - production, procurement, sales and operational planning and production control. So, this criterion finds not only an optimal solution but also optimality, adaptability and flexibility of the production system.

According to the results of research and testing of the models of discrete corrective dynamizing optimization it is estimated that the best results will be shown in cases of combined production of Make-To-Stock and Make-ToOrder and serial production of Make-To-Order.

In the production of Make-To-Stock and by applying linear programming, flexible planning and control, through the means of market research, continuously and approximately corrects upper $Q_{i j}^{g}$ and lower $Q_{i j}^{d}$ limits of the expected demand based on the estimated amount of change in demand $Q d_{i j}$. In case of combined production of Make-To-Stock and Make-To-Order, initial basic plans and their corrections are done more accurately. The initial basic plans determined by linear programming are actually twice adjusted and corrected - by flexible planning and control the upper $Q_{i j}^{g}$ and lower $Q_{i j}^{d}$ limits of the expected demand are continuously corrected and adjusted on the basis of previously collected expected additional orders $Q d_{i j}$. Based on the number of extraordinary, unexpected additional orders $Q v_{i j}$ through methods of simulation and the selected criteria, the correction of the current operational plan of production is being done, i.e., the initial planned amount of product quantities $Q_{i j}^{p}$ are corrected to the amount of $\left(Q_{i j}^{p}\right)^{\prime}$. This helps to achieve production plans with higher level of accuracy, along with higher level of system adaptability to change.

The review of models of production planning in an uncertain environment in last 30 years shows substantial progress in this period [14]. All types of models are discussed and simulation models too, and which emphasize the need for further development of simulation models for conditions of uncertainty.

But, the main prerequisite for success is the use of models and tools which, through simulation, show the results of the decisions beforehand [15]. Particular emphasis is put on the notion that in the contemporary turbulent environment the goal is not to optimize the condition of the enterprise/profit or profit rate, but to maximize flexibility and adaptability as indicators of its dynamic business optimization.

\section{References}

[1] Caramia, M.; Dell' Olmo, P. Effective Resource Management In Manufacturing Systems: Optimization Algorithms For Production Planning, Springer, New York, 2006.

[2] Pinedo, M. L. Planning And Scheduling in Manufacturing and Services, Springer, New York, 2004.

[3] Vollman, T. E.; Berry, W. L.; Whybark, D. C. Manufacturing Planning and Control System, Lavoisier, Paris, 1998

[4] Argonato, Pierluigi et al. Production Planning in Production Networks: Models for Medium and Short-term Planning, Springer, New York, 2008. https://doi.org/10.1007/978-1-84800-058-2

[5] Hackman, S. T. Production Economics, Krieger Publishing Co., Melbourne, Florida/US, 2007.

[6] Yinan, Q.; Tang, M.; Zhang, M. Mass customization in flat organization: The mediating role of supply chain planning and corporation coordination. // Journal of Applied Research and Technology. 12, 2(2014), pp. 171-181. https://doi.org/10.1016/S1665-6423(14)72333-8

[7] Hernandez, J. E.; Mula, J.; Ferriols, F. J. A Reference Model for Conceptual Modelling of Production Planning Processes. // Production Planning \& Control Journal. 8, (2008), pp. 725-734. https://doi.org/10.1080/09537280802476128

[8] Land, M. J.; Gaalman, G. J. C. Production Planning And Control in SMEs: Time For Change. // Production Planning \& Control Journal. 7, (2009), pp. 548-558. https://doi.org/10.1080/09537280903034230

[9] Zhen, M.; Masood, T.; Rahimifard, A.; Weston, R. A Structural Modelling Aproach to Simulating Dynamic Behaviours in Complex Organization. // Production Planning \& Control Journal. 6, (2009), pp. 496-509. https://doi.org/10.1080/09537280902938597

[10] Xue, G.; Offodile, O. F.; Zhou, H.; Troutt, M. D. Integrated Production Planning with Sequence-dependent Family Setup Times. // International Journal of Production Economics. 131, (2011), pp. 674-681. https://doi.org/10.1016/j.ijpe.2011.02.012

[11] Aprile, D.; Garavelli, A. C.; Giannoccaro, I. Operations Planning and Flexibility in a Supply Chain. // Production Planning \& Control Journal. 1, (2005), pp. 21-31. https://doi.org/10.1080/09537280412331313348

[12] Volling, T.; Spengler, T. S. Modeling and Simulation of Order-driven Planning Policies in Build-to-order Automobile Production. // International Journal of Production Economics. 131, (2011), pp. 183-193. https://doi.org/10.1016/j.ijpe.2011.01.008

[13] Lujić, R.; Šarić, T.; Śimunović, G. Primjena ekspertnog sustava pri određivanju klase prioriteta radnog naloga $u$ pojedinačnoj proizvodnji. // Tehnički vjesnik, 14, 12(2007), pp. 65-75. http://hrcak.srce.hr/13514

[14] Mula, J.; Poler, R.; García-Sabater, J. P.; Lario, F.C. Models for Production Planning under Uncertainty: A Review. // International Journal of Production Economics. 103, (2006), pp. 271-285. https://doi.org/10.1016/j.ijpe.2005.09.001

[15] Gupta, J. N. D. An Excursion in Scheduling Theory: An Overview of Scheduling Research in the Twentieth Century. // Production Planning \& Control Journal. 2, (2002), pp. 105-116. https://doi.org/10.1080/09537280110069612

\section{Author's address:}

Ph.D. Borislav Gordić, BIE

Mirako d.o.o. Draškovićeva 57, 10000 Zagreb, Croatia

E-mail: gordicb@yahoo.com

Phone: 00385/91/1710-951 